\title{
Research for Merger and Acquisition of Petrochemical Industries Based on Value Chain
}

\author{
Qing Li ${ }^{1}$, Hao Cheng ${ }^{2}$, Yanjun Liu ${ }^{2}$ \\ ${ }^{1}$ Guangdong Research Institute for International Strategies, Guangzhou, China \\ ${ }^{2}$ Guangdong University of Foreign Studies, Guangzhou, China \\ Email: gwliqing@163.com, 89620751@qq.com, 442783291@qq.com
}

Received November 12, 2012; revised December 15, 2012; accepted December 23, 2012

\begin{abstract}
Based on the analysis of the theories of value chain and multinational merger and acquisition, we research the merger and acquisition of petrochemical industries based on value chain, according to the trait of the value chain of the petrochemical industries. And we propose the implementation process and the integration method for the merger and acquisition of petrochemical industries based on value chain.
\end{abstract}

Keywords: Merger; Value Train; Integration; Pattern

\section{Introduction}

Nowadays the development including structural adjustment, merger and recombination of worldwide petrochemical industries is one of the manifestations of the global distribution of resources such as energy. It mainly reflects the increasingly realized global distribution of the petrochemical industrial chain, including the increasing globalization of exploration, digging, refining process, and also storage and transportation and sales of oil and gas.

In 2009, China became the world's fourth largest crude oil producing country with a crude oil production of 189 million tons which occupied $5.4 \%$ of the world total production and very close to Russia, Saudi Arabia, and the United States. However, in 2009, China became the world's second largest oil consuming countries only after the United States with an oil consumption of as many as 393 million tons. And the ratio of China's dependence on foreign trade was up to $52 \%$ with the oil import amounts to 204 million tons [1]. The data indicates China's supply and demand crisis paradox in the field of energy, making it extreme important to acquire overseas oil resources by means of merger for the safety of China's energy supply.

In a research conducted by the United Stated Bain Company, only $24 \%$ of the enterprises have created new value through merger among the 100 enterprises which had conducted merger and acquisition negotiations and had successfully realized merger [2], while $56 \%$ of the enterprises disparaged their original value even without creating new value, though they had reached a merger agreement at first. Therefore, how to realize the expected goals through sound merger management model in the process of multinational mergers is the main problem the merger enterprises are facing.

Thus, it is significant to research the strategy of merger and acquisition of enterprises as well as strategy for multinational integration of enterprises of petrochemical industries conforms to China's reality with the basis of relative theory and angle of integration of value chains.

\section{Theoretical Basis of the M\&A of the Petrochemical Industries Based on Value Chain}

\subsection{Description of Value Chain Theory}

Potter divided the whole business activity of a corporation into many single specific units in his analysis of corporation competitive advantage [3]. And he called them value creating activity, which functions differently in different sections. Value creating activity mainly includes elementary activity which refers to production, promotion, transportation, and after-sale service and so on, and supplementary activities which refers to supply of raw material, technology, human resources, and finance and so on. The activities connect with each other in the corporation value creating process and constitute the value creating chain, which is the value chain of a corporation [4].

In 1994, Gereffi put forward the framework of Global Commodity Chain, associating value chain with organi- 
zation of globalization. And he conducted a comparative study between the production chains of producer-driven as well as purchaser-driven based on the framework [5]. Early in the 21st century, Gereffi and groups of researchers of the same field agreed to substitute Global Commodity Chain with the term Global Value Chain.

Enterprises of developing countries should seize every opportunity to integrate into the global value chain since the 21st century.

\subsection{Analysis of Petrochemical Industries Value Chain}

The elementary activities of petrochemical industries value chain include Oilfield construction and mining, refining products production, oil and gas storage and transportation, sale of petrochemical products and service and so on [6]. Also, the supplementary activities of petrochemical industries value chain include infra-structure, human resources, technology development and the purchase of enterprises.

1) Oil field exploration and development

Oil field exploration and development is the upstream of petrochemical industries and it is essential for the production of general petrochemical production. It mainly includes oil field exploration, exploitation decision, location layout, and engineering equipment purchase.

2) Refining products production

When oil field construction is completed, the oil will be exploited and become crude oil through oil field and relative equipments. When entering into the refinery, the crude oil will be refined and converted into all kinds of petroleum growing such as gasoline, diesel, and kerosene and so on.

3) Oil and gas storage and transportation

Oil and gas storage and transportation is the transportation process of petrochemical products, by which the products will be transferred to the next producer or dealer, such as transporting the petrochemical products to marketing company and franchiser.

4) Sale of petrochemical products

Sale of petrochemical products is the most important section of petrochemical value chain.

5) Service

Service is the process to maintain and add production value after the sale of production. Derivatives of petrochemical products include gasoline, diesel, and lubricant and so on. They offer different service.

\section{Implementation Process of the Merger and Acquisition of Enterprises Based on Value Chain}

The integration of the value chain after merger is a process of analysis and merger. It defines the power factors of every section by the analysis of value chain and promotes the ability of the factors by merger, through which the creative ability of the whole value chain of enterprises will be developed. The following Figure 1 shows the implementation process of the merger and acquisition of enterprises based on value chain.

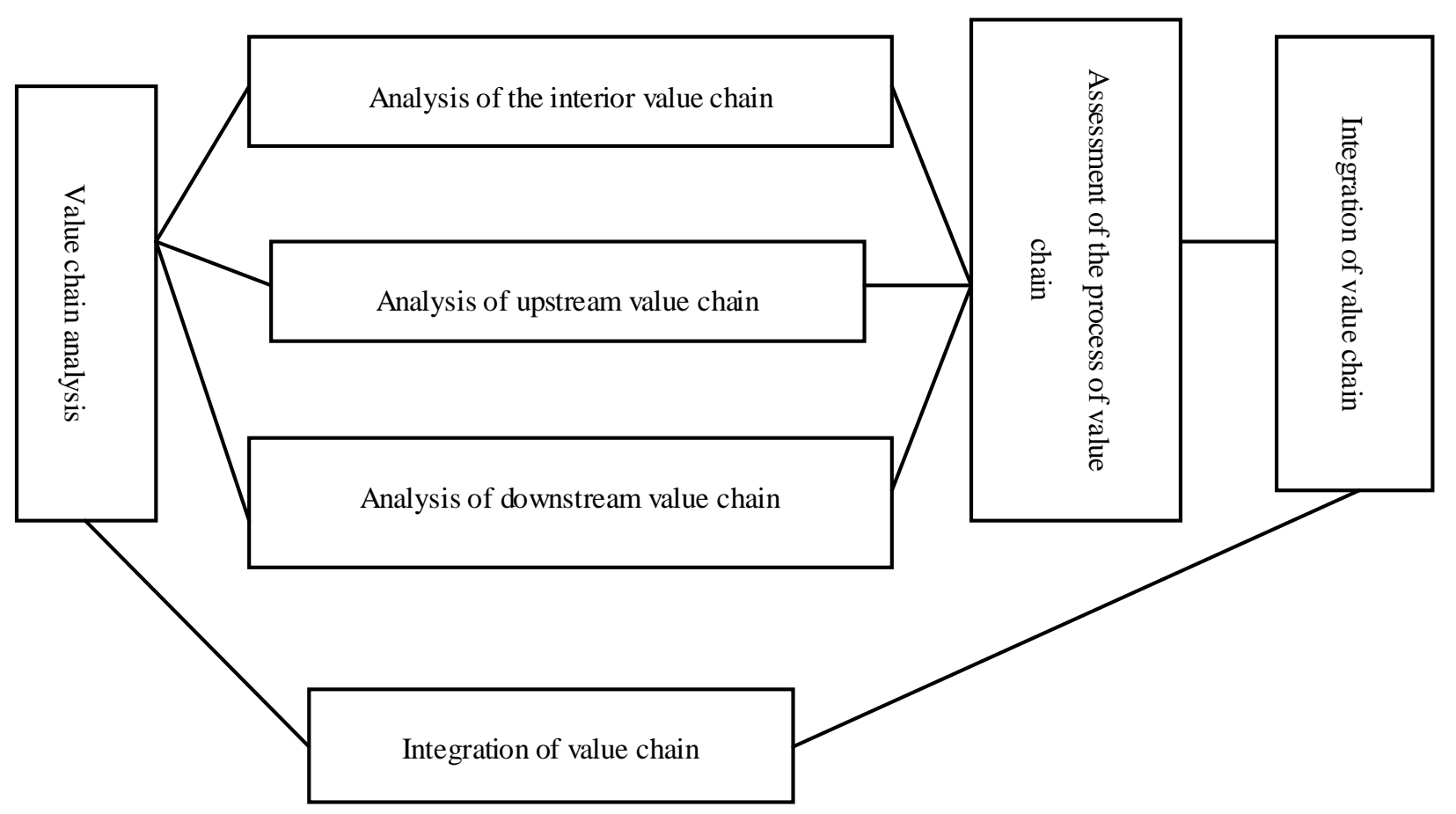

Figure 1. Implementation process of the merger and acquisition of enterprises based on value chain. 


\subsection{Value Chain Analysis}

Value chain analysis is a strategic analyzing instrument, through which we can recognize the value creating process of bilateral corporations involved in the merger. It is the basis of the follow-up integration.

1) Analysis of the interior value chain of enterprises

The interior value chain of enterprises includes basic activity and supplementary activity. Activities of direct and indirect creation of values are included in each of the aforesaid activities.

2) Analysis of the value chain of trades

The value chain of trades of enterprises are divided into two main chain units, respectively upstream of value chain (suppliers) and downstream of value chain (buyers) of the enterprises.

\subsection{Assessment of the Process of Value Chain}

According to Potter value chain theory, the basic and supplementary activities of value chain of enterprises contribute directly to the marginal profit of the enterprises. After assessment of value chain, we should be able to judge which links are the key parts and which activities are redundant in the process of value creation of mutual value chains.

\subsection{Integration of Value Chain}

The integration of value chain after mergers and acquisitions are mainly reform and reorganization to the value creation process in Boundary of Firm. Generally speaking, there are four patterns of integration of enterprises, namely types of absorption, symbiosis, protection and control [7]. These are illustrated as in Figure 2.

1) Absorption integration mode

Under this integration mode, resources of mutual value

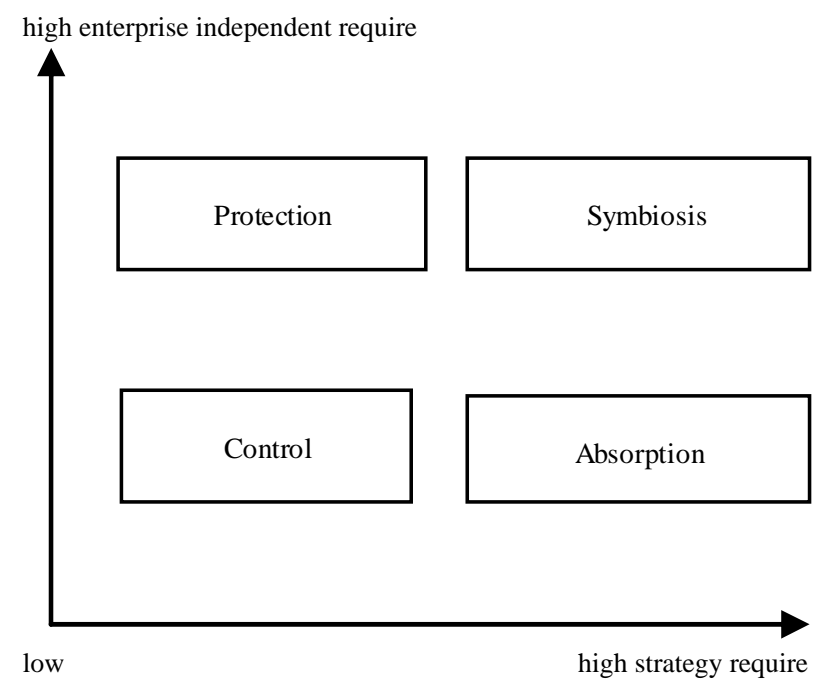

Figure 2. Integration pattern. chains can be shared, repeated link may be eliminated and costs of the operation of the enterprises can be cut off accordingly.

2) Symbiosis integration mode

After the completion of mergers and acquisitions, the two parties involved could still possess independent rights of operation. But they would rely on each other on strategies and shift many of their management skills and abilities.

3) Protection integration mode

After the fulfillment of this integration mode, enterprises of mergers and acquisitions would intervene less about the merged enterprises. Independent rights of operation and management are still possessed by the two sides.

4) Control integration mode

Resources from both sides would be integrated comprehensively by mergers and acquisitions under this mode. In this way, the power and advantage of the resources would be fully used.

\subsection{Analysis about the Effect of the Integration of Value Chain}

The process of integration of value chain is a process of problems found and improved constantly. Therefore, enterprises should assess every operation process in the process of merger integration in order to find problems in time and adjust integration plans and strategies at the same time. A good circulation process of giving feedback and improving in time could be formed accordingly in the process of integration.

\section{Four Elementary Ways Based on Mergers and Acquisitions Integration of Value Chain}

\subsection{Upstream Value Chain Integration}

Upstream value chain of merged enterprises means the value chain of its suppliers to the integration of the upstream value chain suppliers should cut off transaction and operation costs of the enterprises under the condition of the guarantee of the safety of the supply chain of the enterprises after the integration [8].

\subsection{Interior Value Chain Integration}

We can comprehend comprehensively and specifically about which activities could produce value in the operation process through the analysis of the interior value chain of enterprises. To state specifically, the interior value chain of enterprises could be integrated on the following aspects.

1) Integration of enterprises’ infrastructure

Integration of enterprises' infrastructure is part of as- 
sets integration. It's the first section of cross border merger and acquisition integration. Integration of enterprises' infrastructure means merger $s$ and acquisitions integrate the infrastructure and fixed assets of the merged enterprises after the process of mergers and acquisitions. Mergers and acquisitions may assess, absorb or peel the fixed assets of the merged enterprises according to its development strategies and operation targets.

2) Integration of human resource management

Human resource is a special capital resource. It has features of rareness and difficulty in imitation. The structure of human resource of an enterprise determines its knowledge skills, team spirits and creative ability. Therefore, in the process of integration of human resource, the following aspects should be achieved: strengthening communication, keeping talents, settling down general employees properly and establishing efficient system to encourage staff members.

3) Integration of finance

The goal of mergers and acquisitions is to strengthen its competitiveness and create more value through resource integration. Costs management, risk control and optimization of financial management process should be the main items in the process of integration of finance. Synergistic effect between mergers and acquisitions and integration should be tried best to achieve.

There are two alternative patterns for integration of finance: transplantation pattern and blending pattern. Whether to choose overall transferred transplantation pattern or blending pattern with mutual harmony should be determined by the integration process of enterprises.

\subsection{Downstream Value Chain Integration}

Downstream value chain integration means the value chain of dealers. Concerning about particularity of trades of petrol and chemistry, various things should be insured in the process of the integration of the downstream value chain integration. First, plan as a whole the transactions of transportation of crude oil. Secondly, enterprises should be aware of dealing well with host country and taking actions in acquiring preferential policies. Thirdly, hunt for new marketing channels actively and expand distributed market share. Fourthly, launch plans of oil transportation into domestic country in accordance with the country's energy strategy.

\section{Conclusions}

1) Integration based on cross border mergers and acquisitions is a way to integrate and manage the tangible resources of merged enterprises. It means mergers and acquisitions combine the operation of the two sides by virtue of its ability to integrate global resources. Mergers and acquisitions improve its core enterprise's competetiveness and maximize its long term profit through the actions of global allocation of resources, localization of operation management pattern, wide use of global resources and integration of global value chain.

2) Chinese petrochemical enterprises desire to implant global value chain of production of petrochemicals through cross border mergers and acquisitions, and achieve its leap forward development. Chinese petrochemical enterprises become more and more internationalized. Various cases, no matter failed or successful, apply precious resources for studying “Going Out” of Chinese enterprises.

3) The basic integration mode of cross border mergers and acquisitions based on value chain is brought out from the aspect of analysis of value chain of lines. The whole value chain integration is divided into upstream value chain integration, interior value chain integration and downstream value chain integration of the enterprises.

\section{Acknowledgements}

Thanks to the sponsor of fund: Guangdong College Humanities and Social Sciences major research project "Guangdong economic and social development of international strategic studies”, the project number is 10ZGXM63002.

\section{REFERENCES}

[1] Anonymous Person, "Crude Oil Production Amounts 0.2 Billion Tons in China in 2009,” Chinalubricant.com. http://info.chinalubricant.com/web_info/InfoHtml/ReadH tml/20100203/38186677024.htm

[2] M. E. Porter, “Competitive Advantage,” The Free Press, New York, 1985.

[3] Y. Q. Qi, "Study on Integration Strategies after Mergers and Acquisitions," Foreign Economy and Management, Vol. 23, No. 9, 2001, pp. 20-25.

[4] M. Potter, “Advantage of Competitiveness (Translated by Chen Xiaoyue),” Huaxia Press, Beijing, 2005.

[5] G. Gereffi and M. Korzeniewicz, "Commodity Chains and Global Capitalism,” Praege, Westport, 1994.

[6] B. Xu, "Analysis on Value Chain of Chinese Oil Trade," Economic Trade for Foreign Countries in Heilongjiang, Vol. 9, No. 1, 2007, pp. 65-66.

[7] P. C. Haspeslagh and A. B. Farquhar, "The Acquisition Integration Process: A Contingent Framework," 7th Annual International Conference of Strategic Management Society, Boston, 14-17 October 1987.

[8] Y. Z. Zhang, "Study on Upstream of Petrochemical Mergers and Acquisitions Based on Core Competitiveness," Shanghai Jiao Tong University, 2010. 